\title{
Influence of Niobium on Laser De-vitrification of Fe-Si-B Based Amorphous Magnetic Alloys
}

Talukder Alam ${ }^{\mathrm{a}}$, Tushar Borkar ${ }^{\mathrm{a}}$, Sameehan S. Joshi ${ }^{\mathrm{b}}$, Shravan Katakam $^{\mathrm{b}}$, X. Chen ${ }^{\mathrm{c}}$, Narendra B. Dahotre ${ }^{\mathrm{b}}$, Raju V. Ramanujan ${ }^{\mathrm{c}}$, and Rajarshi Banerjee ${ }^{\mathrm{a}}$

${ }^{a}$ Center for Advanced Research and Technology and Department of Materials Science and Engineering, University of North Texas, Denton, Texas, 76201, USA

${ }^{\mathrm{b}}$ Laboratory of Laser Material and Processing and Synthesis, Department of Materials Science and Engineering, University of North Texas, Denton, TX, 76201, USA

${ }^{\mathrm{c}}$ School of Materials Science and Engineering, Nanyang Technological University, 639798, Singapore, Singapore

\begin{abstract}
Laser annealing of $\mathrm{Fe}_{77.5} \mathrm{Si}_{13.5} \mathrm{~B}_{9}$ and $\mathrm{Fe}_{76.5} \mathrm{Si}_{13.5} \mathrm{~B}_{9} \mathrm{Cu}_{1}$ amorphous melt-spun ribbons was carried out. In both alloys, it was found that devitrification occurred, leading to the nucleation of a high density of refined $\alpha-\mathrm{Fe}(\mathrm{Si})$ nanocrystals within the amorphous matrix. Interestingly, when laser processed under identical conditions, $\mathrm{Fe}_{74.5} \mathrm{Si}_{13.5} \mathrm{~B}_{9} \mathrm{Nb}_{3}$, and $\mathrm{Fe}_{73.5} \mathrm{Si}_{13.5} \mathrm{~B}_{9} \mathrm{Nb}_{3} \mathrm{Cu}_{1}$ (FINEMET) amorphous melt-spun ribbons did not exhibit devitrification or copper clustering. Differences in the magnetic properties were observed, with the $\mathrm{Fe}_{77.5} \mathrm{Si}_{13.5} \mathrm{~B}_{9}$ and $\mathrm{Fe}_{76.5} \mathrm{Si}_{13.5} \mathrm{~B}_{9} \mathrm{Cu}_{1}$ alloys exhibiting higher saturation magnetization $\left(\mathrm{M}_{\mathrm{S}}\right)$ and higher coercivity $\left(\mathrm{H}_{\mathrm{C}}\right)$ values while $\mathrm{Fe}_{74.5} \mathrm{Si}_{13.5} \mathrm{~B}_{9} \mathrm{Nb}_{3}$, and $\mathrm{Fe}_{73.5} \mathrm{Si}_{13.5} \mathrm{~B}_{9} \mathrm{Nb}_{3} \mathrm{Cu}_{1}$ alloys exhibited lower values of both these properties. These results clearly reveal the enhanced stability of the amorphous phase due to the addition of $\mathrm{Nb}$ in $\mathrm{Fe}-\mathrm{Si}-\mathrm{B}$ based melt-spun samples.
\end{abstract}

\section{Keywords}

Laser devitrification; Magnetic measurements; Atom probe tomography (APT); Soft magnetric material; Transmission electron microscopy (TEM).

Corresponding author. Tel.: +1 940891 6812; Fax: +1 9405654824

E-mail address: Rajarshi.Banerjee@unt.edu (Rajarshi Banerjee) 


\section{Introduction}

Fe-Si-B based amorphous alloys exhibit superior soft magnetic properties in their partially de-vitrified condition since it has been well established that nanocrystals embedded in an amorphous matrix lead to optimum properties [1-8]. Such partial devitrification can be achieved through furnace annealing the amorphous melt-spun ribbons for various temperaturetime combinations. However, if the annealing leads to substantial growth of the nanocrystals, then the soft magnetic properties are degraded due to the dependence of coercivity on the grain size. Based on the experimental measurements of coercivity for a large number of different amorphous magnetic alloys, Herzer concluded that coercivity is lowest for grain sizes which are either more than $100 \mu \mathrm{m}$ or less than $40 \mathrm{~nm}$ [7,8]. Based on these considerations it was previously established that a homogeneous distribution of nanocrystals within an amorphous matrix can be achieved in the composition $\mathrm{Fe}_{73.5} \mathrm{Si}_{13.5} \mathrm{~B}_{9} \mathrm{Nb}_{3} \mathrm{Cu}_{1}$, commonly referred to as FINEMET. Partially de-vitrified FINEMET consists of $10-15 \mathrm{~nm} \alpha-\mathrm{Fe}(\mathrm{Si})$ nanocrystals embedded in an amorphous matrix. It is well known that the addition of $\mathrm{Cu}$ to the $\mathrm{Fe}-\mathrm{Si}$-B alloy results in clustering of this alloying element, with the $\mathrm{Cu}$-rich clusters acting as potent nucleation sites for the $\alpha-\mathrm{Fe}(\mathrm{Si})$ nanocrystals, while $\mathrm{Nb}$ restricts coarsening of these nanocrystals [9-15]. Thus these alloying additions result in a much finer microstructure with much lower coercivity but somewhat lower saturation magnetization compared to ternary Fe-Si-B based compositions [16]. This can be attributed in part to the lower concentration of Fe in FINEMET.

While previous studies have largely focused on furnace annealing for devitrification of these amorphous soft magnetic alloys, some recent studies have investigated devitrification via rapid annealing using specifically designed furnaces $[17,18]$ as well as via laser processing [19-

21]. The results of rapid annealing (heating rates of 100-200 K/s) melt-spun ribbons of 
$\mathrm{Fe}_{73.5} \mathrm{Si}_{13.5} \mathrm{~B}_{9} \mathrm{Nb}_{3} \mathrm{Cu}_{1}$ on the microstructure [18] and magnetic properties [17] are quite interesting. While the general trends of devitrification are similar to those observed in furnace annealing, there is a refinement in the size of the $\alpha-\mathrm{Fe}(\mathrm{Si})$ nanocrystals in the rapidly annealed samples [18]. Furthermore, while $\mathrm{Cu}$ clustering is also observed prior to the onset of primary crystallization of $\alpha-\mathrm{Fe}(\mathrm{Si})$ nanocrystals (in rapidly annealed samples), the previous study reports a tendency for coarsening of these $\mathrm{Cu}$-rich clusters within a short time period [18]. Additionally, the mechanism of primary crystallization of $\alpha-\mathrm{Fe}(\mathrm{Si})$ nanocrystals proposed is somewhat different than that proposed previously by Hono et. al. [10]. Thus, while it has been previously proposed by Hono et. al. [10] that $\mathrm{Cu}$-rich clusters act as heterogeneous nucleation sites for $\alpha$ $\mathrm{Fe}(\mathrm{Si})$ nanocrystals within the amorphous matrix, Pradeep et. al. [18] proposed that Cu-rich clusters create local compositional fluctuations of $\mathrm{Fe}$ and $\mathrm{Si}$ in the adjacent matrix regions, and these compositional fluctuations eventually result in primary crystallization of $\alpha-\mathrm{Fe}(\mathrm{Si})$ nanocrystals. Crobak et. al. [19] studied the influence of $\mathrm{Nb}$ on the first stage of crystallization in Fe-Nb-B amorphous alloys. The experimental results clearly indicated that the nanocrystallization temperature as well as the activation enthalpy for the nanocrystallization process increased with increasing $\mathrm{Nb}$ content. The proposed rationale [19] was that $\mathrm{Nb}$ addition in the amorphous $\mathrm{Fe}-\mathrm{Nb}-\mathrm{B}$ alloys slows down the diffusion process leading to an increase in the crystallization or de-vitrification temperature of these alloys via the formation of Fe nanograins within the amorphous matrix followed by their growth.

A different set of studies have recently been conducted on laser-induced nanocrystallization, which have revealed that after irradiation with a continuous wave laser beam with a Gaussian profile, there is a transition in microstructure across the laser track, from partial devitrification in the center of the track to complete devitrification at the edge of the track [20- 
22]. The behavior and nature of this laser-induced nanocrystallization has been previously modeled and rationalized [20,21]. Furthermore, the laser devitrification process is site-specific, opening up many possibilities of designing patterned crystallized regions [23-25] that could lead to a wide array of composite functional applications.

The focus of the present study is to compare and contrast laser annealing of amorphous $\mathrm{Fe}_{77.5} \mathrm{Si}_{13.5} \mathrm{~B}_{9}, \quad \mathrm{Fe}_{73.5} \mathrm{Si}_{13.5} \mathrm{~B}_{9} \mathrm{Nb}_{3} \mathrm{Cu}_{1}, \quad \mathrm{Fe}_{74.5} \mathrm{Si}_{13.5} \mathrm{~B}_{9} \mathrm{Nb}_{3}$, and $\mathrm{Fe}_{73.5} \mathrm{Si}_{13.5} \mathrm{~B}_{9} \mathrm{Nb}_{3} \mathrm{Cu}_{1}$ (FINEMET) alloys, to specifically address the impact of alloying on the respective tendencies for devitrification, microstructural evolution as well as soft magnetic properties.

\section{Experimental Procedure}

The experimental studies were conducted on melt-spun ribbon samples, with nominal compositions of $\mathrm{Fe}_{77.5} \mathrm{Si}_{13.5} \mathrm{~B}_{9}, \mathrm{Fe}_{76.5} \mathrm{Si}_{13.5} \mathrm{~B}_{9} \mathrm{Cu}_{1}, \mathrm{Fe}_{74.5} \mathrm{Si}_{13.5} \mathrm{~B}_{9} \mathrm{Nb}_{3}$, and $\mathrm{Fe}_{73.5} \mathrm{Si}_{13.5} \mathrm{~B}_{9} \mathrm{Nb}_{3} \mathrm{Cu}_{1}$, with an average thickness of $20 \mu \mathrm{m}$, prepared in a laboratory scale melt-spinning setup. Laser thermal treatment of metallic glass foils was carried out employing a continuous wave Nd-YAG laser (wavelength $=1064 \mathrm{~nm}$ wavelength, laser beam diameter $=0.6 \mathrm{~mm}$ on the sample surface, input power $=100 \mathrm{~W})$. Samples were scanned at beam scanning speed of $500 \mathrm{~mm} / \mathrm{s}$ and laser track overlap of $0.3 \mathrm{~mm}$. Combination of these laser parameters resulted in laser fluence of 0.42 $\mathrm{J} / \mathrm{mm}^{2}$. This particular set of laser processing parameters was chosen based on the past experience about the studies of laser thermal treated Fe based metallic glasses, reported in the previously published works [20, 22-25] by the present research group. Thin film transmission

electron microscopy (TEM) samples and needle shaped atom probe tomography (APT) samples were prepared using an FEI Nova 200 focused ion beam system (FIB/SEM). TEM characterization was done on an FEI Tecnai F20 TEM with a field emission source. APT was conducted on an Imago LEAP 3000X HR through laser ionization with a pulse fraction of 0.2, 
pulse rate of $160 \mathrm{kHz}$, temperature of $30 \mathrm{~K}$, and a pressure of 1 x $10^{-10} \mathrm{~Pa}$. Magnetization measurements were performed by means of a vibrating sample magnetometer (VSM-Lakeshore 7404) using a maximum magnetic field of $1 \mathrm{~T}$.

\section{X-ray Diffraction and Transmission Electron Microscopy}

The x-ray diffraction patterns of laser annealed melt-spun ribbons of $\mathrm{Fe}_{77.5} \mathrm{Si}_{13.5} \mathrm{~B}_{9}$, $\mathrm{Fe}_{76.5} \mathrm{Si}_{13.5} \mathrm{~B}_{9} \mathrm{Cu}_{1}, \mathrm{Fe}_{74.5} \mathrm{Si}_{13.5} \mathrm{~B}_{9} \mathrm{Nb}_{3}$, and $\mathrm{Fe}_{73.5} \mathrm{Si}_{13.5} \mathrm{~B}_{9} \mathrm{Nb}_{3} \mathrm{Cu}_{1}$, are presented in Figs. 1(a), (b), (c) and (d), respectively. While Figs. 1(a) and (b), corresponding to the laser-annealed $\mathrm{Fe}_{77.5} \mathrm{Si}_{13.5} \mathrm{~B}_{9}$, and $\mathrm{Fe}_{76.5} \mathrm{Si}_{13.5} \mathrm{~B}_{9} \mathrm{Cu}_{1}$ compositions, clearly exhibit the (011), (002), and (112) peaks corresponding to the $\alpha-\mathrm{Fe}(\mathrm{Si})$ phase, Figs. 1(c) and (d), corresponding to the laser-annealed $\mathrm{Fe}_{74.5} \mathrm{Si}_{13.5} \mathrm{~B}_{9} \mathrm{Nb}_{3}$, and $\mathrm{Fe}_{73.5} \mathrm{Si}_{13.5} \mathrm{~B}_{9} \mathrm{Nb}_{3} \mathrm{Cu}_{1}$ melt-spun ribbons, do not exhibit any sharp crystalline peaks, but rather exhibit broad humps, typically characteristic of amorphous phases. Since crystalline peaks were only observed in the $\mathrm{Fe}_{77.5} \mathrm{Si}_{13.5} \mathrm{~B}_{9}$ and $\mathrm{Fe}_{76.5} \mathrm{Si}_{13.5} \mathrm{~B}_{9} \mathrm{Cu}_{1}$ alloys, transmission electron microscopy (TEM) investigations were carried out on only these two laserannealed alloys. Figs. 2(a), (b), and (c) show the electron diffraction pattern, lower magnification dark-field image, and higher magnification dark-field image, respectively from the $\mathrm{Fe}_{77.5} \mathrm{Si}_{13.5} \mathrm{~B}_{9}$ alloy, while Figs. 2(d), (e), and (f) show corresponding diffraction patterns and dark-field images from the $\mathrm{Fe}_{76.5} \mathrm{Si}_{13.5} \mathrm{~B}_{9} \mathrm{Cu}_{1}$ alloy. The polycrystalline nature of both these laser-annealed alloys is evident from the diffraction patterns shown in Figs. 2(a) and (b). The rings in both these patterns could be consistently indexed based on the $\alpha-\mathrm{Fe}(\mathrm{Si})$ phase. Comparing the dark-field images from the two alloys, both samples exhibit similar average sizes of the $\alpha-\mathrm{Fe}(\mathrm{Si})$ nanocrystals, with the nanocrystals being marginally more refined in the $\mathrm{Fe}_{76.5} \mathrm{Si}_{13.5} \mathrm{~B}_{9} \mathrm{Cu}_{1}$ alloy compared with the $\mathrm{Fe}_{77.5} \mathrm{Si}_{13.5} \mathrm{~B}_{9}$ alloy. The average size of the $\alpha-\mathrm{Fe}(\mathrm{Si})$ nanocrystals in both cases was found to be $30 \mathrm{~nm} \pm 10 \mathrm{~nm}$. 


\section{Atom Probe Tomography}

Atom probe tomography reconstructions of the laser annealed $\mathrm{Fe}_{77.5} \mathrm{Si}_{13.5} \mathrm{~B}_{9}$ melt-spun sample are shown in Figs. 3(a) and (b). While Fig. 3(a) shows all the Si (green) and B (blue) ions within an $10 \mathrm{~nm}$ slice of the APT reconstruction, Fig. 3(b) shows the same ions together with an isoconcentration surface (also referred to as isosurface in an abbreviated form) corresponding to 11 at\% $\mathrm{Si}$, clearly delineating the $\alpha-\mathrm{Fe}(\mathrm{Si})$ crystals (green regions) from the surrounding amorphous matrix (in blue). The $\alpha-\mathrm{Fe}(\mathrm{Si})$ crystals shown in these reconstructions are in the same size range as those revealed by the dark-filed TEM micrographs (shown in Figs. 2(b) and (c)). The averaged compositional profiles for $\mathrm{Fe}, \mathrm{Si}$, and $\mathrm{B}$, measured across the same isosurfaces, using the proximity histogram analysis are presented in Fig. 3(c). The partitioning of Si into the $\alpha-\mathrm{Fe}(\mathrm{Si})$ crystals and B into the amorphous matrix occurs over a region of $\sim 2 \mathrm{~nm}$ across the $\alpha$ $\mathrm{Fe}(\mathrm{Si}) /$ amorphous interface with the long-range $\mathrm{Si}$ content being 16 at $\%$ in the $\alpha-\mathrm{Fe}(\mathrm{Si})$ phase while the B content is $\sim 24$ at $\%$ in the amorphous phase. These values appear to be quite similar to those reported in the previous study on laser-annealed and partially devitrified $\mathrm{Fe}_{77.5} \mathrm{Si}_{13.5} \mathrm{~B}_{9}$ melt-spun ribbons [22].

APT results from the laser devitrified $\mathrm{Fe}_{76.5} \mathrm{Si}_{13.5} \mathrm{~B}_{9} \mathrm{Cu}_{1}$ ribbons are shown in Fig. 4. The reconstructions shown in Figs. 4(a), (b) and (c) depict, (a) all Si (green), B (blue), and Cu(red) ions within a $10 \mathrm{~nm}$ slice, (b) $\mathrm{Si}$ and B ions together with 11 at $\% \mathrm{Si}$ and 4 at\% $\mathrm{Cu}$ isosurfaces delineating the $\alpha-\mathrm{Fe}(\mathrm{Si})$ nanocrystals and the $\mathrm{Cu}$ clusters respectively, and (c) a $90^{\circ}$ rotated view of the same reconstruction shown in (b). It should be noted that in most cases, the $\mathrm{Cu}$-rich clusters, delineated by the 4 at $\% \mathrm{Cu}$ isosurface, lie at the $\alpha-\mathrm{Fe}(\mathrm{Si}) /$ amorphous interfaces. The proximity histogram profiles of $\mathrm{Si}, \mathrm{B}$, and $\mathrm{Cu}$ across the $\alpha-\mathrm{Fe}(\mathrm{Si}) /$ amorphous interface are shown in Fig. 4(d). The long-range Si content in the $\alpha-\mathrm{Fe}(\mathrm{Si})$ phase is $\sim 17$ at $\%$ while the B content is 
$\sim 24$ at $\%$ in the amorphous phase, similar to case of the partially devitrified $\mathrm{Fe}_{77.5} \mathrm{Si}_{13.5} \mathrm{~B}_{9}$ sample. One-dimensional composition profiles for $\mathrm{Si}, \mathrm{B}$, and $\mathrm{Cu}$ across a $\mathrm{Cu}$-rich cluster, along two perpendicular directions, are shown in Figs. 4(e) and (f) respectively. This $\mathrm{Cu}$ cluster resides at the interface between two $\alpha-\mathrm{Fe}(\mathrm{Si})$ nanocrystals and the surrounding amorphous matrix. The composition profiles were computed by averaging across a cylinder $3 \mathrm{~nm}$ in diameter. While this cylinder (shown in the inset of the figure) is oriented such that it crosses two amorphous/Cu/amorphous interfaces (Fig. 4(e)), the cylinder crosses two $\alpha-\mathrm{Fe}(\mathrm{Si}) / \mathrm{Cu} / \alpha-\mathrm{Fe}(\mathrm{Si})$ interfaces in Fig. 4(f). Based on both profiles, the maximum $\mathrm{Cu}$ content within this $\mathrm{Cu}$-rich cluster is $\sim 46$ at\% while there is $\sim 12$ at\% $\mathrm{Si}$, and nearly no B within these clusters. The remaining $\sim 42$ at\% is these $\mathrm{Cu}$-rich clusters can be attributed to retained Fe.

Two representative APT reconstructions from the laser-annealed $\mathrm{Fe}_{74.5} \mathrm{Si}_{13.5} \mathrm{~B}_{9} \mathrm{Nb}_{3}$ and $\mathrm{Fe}_{73.5} \mathrm{Si}_{13.5} \mathrm{~B}_{9} \mathrm{Nb}_{3} \mathrm{Cu}_{1}$ (FINEMET) amorphous melt-spun ribbons are shown in Figs. 5(a) and (c) respectively. Both reconstructions show the raw plot of all ions within a $10 \mathrm{~nm}$ slice of the sample. Based on the visual rendition of these reconstructions as well as the corresponding onedimensional composition profiles across the axis of these cylindrical reconstructions (Figs. 5(b) and (d)), it can be concluded that both these samples, $\mathrm{Fe}_{74.5} \mathrm{Si}_{13.5} \mathrm{~B}_{9} \mathrm{Nb}_{3}$ and $\mathrm{Fe}_{73.5} \mathrm{Si}_{13.5} \mathrm{~B}_{9} \mathrm{Nb}_{3} \mathrm{Cu}_{1}$ (FINEMET), remain compositionally homogeneous, despite being subjected to the same laser annealing treatment experienced by the previous two, $\mathrm{Fe}_{77.5} \mathrm{Si}_{13.5} \mathrm{~B}_{9}$ and $\mathrm{Fe}_{73.5} \mathrm{Si}_{13.5} \mathrm{~B}_{9} \mathrm{Nb}_{3} \mathrm{Cu}_{1}$ samples.

\section{Magnetic Properties}

Vibrating sample magnetometer results for all four laser annealed samples are presented in Fig. 6. The values of saturation magnetization $\left(M_{s}\right)$ are higher for the partially devitrified $\mathrm{Fe}_{77.5} \mathrm{Si}_{13.5} \mathrm{~B}_{9}$ and $\mathrm{Fe}_{76.5} \mathrm{Si}_{13.5} \mathrm{~B}_{9} \mathrm{Cu}_{1}$ samples compared to the amorphous $\mathrm{Fe}_{74.5} \mathrm{Si}_{13.5} \mathrm{~B}_{9} \mathrm{Nb}_{3}$ and 
$\mathrm{Fe}_{73.5} \mathrm{Si}_{13.5} \mathrm{~B}_{9} \mathrm{Nb}_{3} \mathrm{Cu}_{1}$ (FINEMET) samples after laser annealing. Table $\mathrm{I}$ lists the $\mathrm{M}_{\mathrm{s}}$ and coercivity $\left(H_{c}\right)$ values for all four samples after laser annealing. The $M_{s}$ values decrease from a maximum of $124 \mathrm{emu} / \mathrm{g}$ to a minimum value of $103 \mathrm{emu} / \mathrm{g}$ with the difference being $21 \mathrm{emu} / \mathrm{g}$, while the coercivity $\left(\mathrm{H}_{\mathrm{c}}\right)$ values exhibit a substantially larger relative difference from a maximum of $581 \mathrm{~A} / \mathrm{m}$ to a minimum of $72 \mathrm{~A} / \mathrm{m}$ (difference of $509 \mathrm{~A} / \mathrm{m}$ ). As expected the laserannealed $\mathrm{Fe}_{74.5} \mathrm{Si}_{13.5} \mathrm{~B}_{9} \mathrm{Nb}_{3}$ and $\mathrm{Fe}_{73.5} \mathrm{Si}_{13.5} \mathrm{~B}_{9} \mathrm{Nb}_{3} \mathrm{Cu}_{1}$ (FINEMET) samples, that neither exhibited any devitrification nor any compositional partitioning/clustering, had the lowest values of coercivity $\left(\mathrm{H}_{\mathrm{c}}\right), 88$ and $72 \mathrm{~A} / \mathrm{m}$ respectively while the partially devitrified samples of composition, $\mathrm{Fe}_{77.5} \mathrm{Si}_{13.5} \mathrm{~B}_{9}$ and $\mathrm{Fe}_{76.5} \mathrm{Si}_{13.5} \mathrm{~B}_{9} \mathrm{Cu}_{1}$, containing nanocrystals of $\alpha-\mathrm{Fe}(\mathrm{Si})$ exhibited substantially higher $\mathrm{H}_{\mathrm{c}}$ values of $581 \mathrm{~A} / \mathrm{m}$ and $271 \mathrm{~A} / \mathrm{m}$ respectively.

According to the Herzer model, the grain size has a strong influence on $\mathrm{H}_{\mathrm{c}}[7,8]$, and when grain sizes are less than $40 \mathrm{~nm}$, the coercivity drastically drops, a result of the ferromagnetic exchange interactions allowing the randomly aligned moments to cancel out. Therefore, in systems with crystal sizes below the ferromagnetic exchange length, a group of randomly aligned moments average out and the overall contribution of unaligned moments to the magneto-crystalline anisotropy is consequently drastically reduced. Since magneto-crystalline anisotropy is the primary factor determining coercivity, the reduction in magneto-crystalline anisotropy due to reduced grain size leads to low coercivity values. The typical exchange length for $\mathrm{Fe}-20$ at $\% \mathrm{Si}$ crystals, calculated from the exchange stiffness and the magneto-crystalline anisotropy factor was determined to be $\sim 35 \mathrm{~nm}$ [7]. Since the $\alpha-\mathrm{Fe}(\mathrm{Si})$ crystals in both the $\mathrm{Fe}_{77.5} \mathrm{Si}_{13.5} \mathrm{~B}_{9}$ and $\mathrm{Fe}_{73.5} \mathrm{Si}_{13.5} \mathrm{~B}_{9} \mathrm{Nb}_{3} \mathrm{Cu}_{1}$ laser devitrified ribbons contain $\sim 16-17$ at $\% \mathrm{Si}$, based on the atom probe studies, the ferromagnetic exchange length in the present experimental case should be very similar to the predicted value for 20 at $\%$ Si. However, as noted earlier, there is a 
marginal reduction in the average size of the $\alpha-\mathrm{Fe}(\mathrm{Si})$ nanocrystals in case of the laser devitrified $\mathrm{Fe}_{76.5} \mathrm{Si}_{13.5} \mathrm{~B}_{9} \mathrm{Cu}_{1}$ samples as compared to the $\mathrm{Fe}_{77.5} \mathrm{Si}_{13.5} \mathrm{~B}_{9}$ sample. Furthermore, since the sizes of the nanocrystals in both cases, $30 \mathrm{~nm} \pm 10 \mathrm{~nm}$, are close to the calculated exchange length of $\sim 35 \mathrm{~nm}$, the small difference in the average sizes of the nanocrystals in both cases results in a substantial reduction in the coercivity $\left(\mathrm{H}_{\mathrm{c}}\right)$. Thus, while the $\mathrm{Fe}_{77.5} \mathrm{Si}_{13.5} \mathrm{~B}_{9}$ sample exhibited $\mathrm{H}_{\mathrm{c}}=580.9 \mathrm{~A} / \mathrm{m}$, the $\mathrm{Fe}_{76.5} \mathrm{Si}_{13.5} \mathrm{~B}_{9} \mathrm{Cu}_{1}$ sample exhibited $\mathrm{H}_{\mathrm{c}}=270.6 \mathrm{~A} / \mathrm{m}$, less than half the former value.

\section{Multiphysics Computational Modeling}

A multiphysics based three dimensional finite element (FE) heat transfer model on $\mathrm{COMSOL}^{\mathrm{TM}}$ platform was developed to predict the thermal histories generated during laser treatment of metallic glass ribbons. The values of factors critically influencing microstructural developmentsuch as heating and cooling rates, and peak temperature attained during laser thermal treatment were extracted from the model. The computational model consisted of geometrical simulation of Fe based metallic glass ribbon in the form of a rectangular block of 50 $\mathrm{x} 1.2 \times 0.0023 \mathrm{~cm}^{3}$ dimensions. This block was meshed with extra fine mesh $($ mesh size $=0.1$ $\mathrm{mm})$.

Based on the principle of conservation of energy, the transient temperature fields, developed while the laser beam traverses over the sample surface, can be expressed by Eq. 1 .

$\rho C_{\mathrm{r}}\left(\frac{\partial T}{\partial !}\right)_{(x, y, z)}=k^{c}\left[\left(\frac{\partial T}{\partial x}\right)_{\partial y, t)}-\left(\frac{\partial T}{\partial y}\right)_{(x, y, i)}+\left(\frac{\partial T}{\partial L}\right)_{(x, y, t)}\right]$

where $\rho$ is the density, $\mathrm{C}_{P}$ is the specific heat capacity, and k' is the thermal conductivity of the material. As the temperature dependent thermo-physical properties are not available in the open 
literature; the constant values (Table II) were used. The three dimensional heat flux $\left(\mathrm{Q}_{\mathrm{x}, \mathrm{y}, \mathrm{z}}\right)$ within the moving laser beam was expressed in the form of Gaussian distribution)

Further, inward heat flux was assigned on top surface to incorporate incoming laser beam, and heat loses due to simultaneous convection and radiation were taken in to account.

Typically, the heat transfer coefficient under natural convection has been reported to be of the order of tens of $\mathrm{W} / \mathrm{m}^{2} \mathrm{~K}$, [26-28] therefore it was set as $10 \mathrm{~W} / \mathrm{m}^{2} / \mathrm{K}$ in current FE model. Although the emissivity ( $\square$ ) varies signficantly with temperature there is paucity of the temperature dependent data in the open literature. Furthermore, the emissivity also depends on surface condition of the sample and reported to vary between 0.07 to 0.79 [29]. In light of this, in the present case a constant value of 0.7 was considered for emissivity, which is typical for unpolished surfaces. In addition, the current model took into account the heat transfer on the surfaces via convection and radiation modes. As the evolution of temperature field depends on the laser beam scanning speed, a finite residence time based quasi-stationary laser beam approach was adopted in the model. Other modeling assumptions were: (i) the material was isotropic and opaque, (ii) if any material was evaporated/ablated, it was considered to be transparent and did not interfere with the incident laser beam, and (iii) multiple reflections of laser radiation within the laser-material interaction zone are neglected. The further details of mathematical formulation and logic behind the current model can be found in the previous publications [20-25]. The multiphysics computational model incorporating the above predicted approach the temperature profile as a function of time. These results were correlated with the microstructural evolution as a result of laser thermal treatment. 
Based on this multiphysics computational model, the thermal history experienced by the samples in the present study, during laser annealing is shown in Fig. 7. The average heating rate during laser annealing was computed to be $68 \times 10^{4} \mathrm{~K} / \mathrm{s}$, the average cooling rate was $14 \times 10^{4}$ $\mathrm{K} / \mathrm{s}$, and the peak temperature in the profile was $1087 \mathrm{~K}$.

\section{Influence of Composition on Devitrification During Laser Annealing}

The results of the present study clearly reveal that laser annealing of only two of the compositions, $\mathrm{Fe}_{77.5} \mathrm{Si}_{13.5} \mathrm{~B}_{9}$, and $\mathrm{Fe}_{76.5} \mathrm{Si}_{13.5} \mathrm{~B}_{9} \mathrm{Cu}_{1}$ partially devitrifies these melt-spun alloys, while the other two, $\mathrm{Fe}_{74.5} \mathrm{Si}_{13.5} \mathrm{~B}_{9} \mathrm{Nb}_{3}$ and $\mathrm{Fe}_{73.5} \mathrm{Si}_{13.5} \mathrm{~B}_{9} \mathrm{Nb}_{3} \mathrm{Cu}_{1}$, neither exhibit any devitrification nor any other compositional changes, such as clustering, due to the laser processing. Therefore, the two effects of alloying on laser devitrification are as follows:

i. Addition of $\mathrm{Nb}$ to $\mathrm{Fe}-\mathrm{Si}-\mathrm{B}$ or $\mathrm{Fe}-\mathrm{Si}-\mathrm{B}-\mathrm{Cu}$ hinders devitrification and stabilizes the amorphous phase.

ii. Comparing $\mathrm{Fe}_{77.5} \mathrm{Si}_{13.5} \mathrm{~B}_{9}$, and $\mathrm{Fe}_{76.5} \mathrm{Si}_{13.5} \mathrm{~B}_{9} \mathrm{Cu}_{1}$ compositions, while both exhibit partial devitrification due to laser annealing, there is a marginally refined microstructure, with finer scale $\alpha-\mathrm{Fe}(\mathrm{Si})$ nanocrystals in case of the latter alloy as compared with the former alloy.

The first result can be rationalized based on the diffusivities of the various elements involved in the devitrification of the amorphous phase or primary crystallization of $\alpha-\mathrm{Fe}(\mathrm{Si})$ in case of $\mathrm{Fe}-\mathrm{Si}$ B based alloys. Thus, $\mathrm{Si}, \mathrm{B}$, and $\mathrm{Nb}$, all partition during the primary crystallization process. The role of $\mathrm{Cu}$ is largely at an earlier stage, prior to primary crystallization, when $\mathrm{Cu}$ tends to cluster within the amorphous matrix and acts a heterogeneous nucleation sites for the of $\alpha-\mathrm{Fe}(\mathrm{Si})$ nanocrystals. While $\mathrm{Si}$ and $\mathrm{B}$ have relatively high diffusivities, $\mathrm{Nb}$ is a rather slow diffuser in bcc Fe. Based on previously reported experimental results [30], the primary crystallization of $\alpha$ - 
$\mathrm{Fe}(\mathrm{Si})$ nanocrystals in the amorphous matrix is accompanied by the rejection of $\mathrm{B}$ and $\mathrm{Nb}$ from these nanocrystals while Si diffuses into these nanocrystals. Therefore, it is likely that the primary crystallization of $\alpha-\mathrm{Fe}(\mathrm{Si})$ nanocrystals is kinetically constrained by the addition of $\mathrm{Nb}$ to Fe-Si-B. Considering the high heating and cooling rates involved during laser annealing, greater than $10^{5} \mathrm{~K} / \mathrm{s}$, as computed by the multi-physics modeling discussed earlier, it is unlikely that there is sufficient time for $\mathrm{Nb}$ atoms to diffuse over the length scales required to initiate nucleation of $\alpha-\mathrm{Fe}(\mathrm{Si})$ nanocrystals.

With regard to the marginally finer scale of the $\alpha-\mathrm{Fe}(\mathrm{Si})$ nanocrystals in the $\mathrm{Fe}_{76.5} \mathrm{Si}_{13.5} \mathrm{~B}_{9} \mathrm{Cu}_{1}$ composition compared to the $\mathrm{Fe}_{77.5} \mathrm{Si}_{13.5} \mathrm{~B}_{9}$ composition, the role of $\mathrm{Cu}$ in the former alloy is evident. As reported previously in conventionally annealed [30] and rapidly annealed [31] Fe-Si-B-Cu melt-spun alloys, $\mathrm{Cu}$ has a strong tendency to form clusters in the amorphous matrix prior to the onset of primary crystallization. The results of the present investigation also reveal the formation of distinct $\mathrm{Cu}$-rich clusters at the interface between the $\alpha$ $\mathrm{Fe}(\mathrm{Si})$ nanocrystals and the adjacent amorphous matrix in laser annealed $\mathrm{Fe}_{76.5} \mathrm{Si}_{13.5} \mathrm{~B}_{9} \mathrm{Cu}_{1}$ (Fig. 4). Therefore, despite the high heating rate) involved in laser annealing, there is sufficient time for short-range diffusion of $\mathrm{Cu}$ to take place within the amorphous matrix, prior to the onset of primary crystallization of $\alpha-\mathrm{Fe}(\mathrm{Si})$ nanocrystals. This is also in agreement with similar $\mathrm{Cu}$ clustering observed during rapidly annealed samples $(100-200 \mathrm{~K} / \mathrm{s})$ [18]. These homogeneously distributed $\mathrm{Cu}$ clusters act as effective heterogeneous nucleation sites for $\alpha-\mathrm{Fe}(\mathrm{Si})$ nanocrystals. Consequently, a refinement in the size scale of the $\alpha-\mathrm{Fe}(\mathrm{Si})$ nanocrystals is expected in case of $\mathrm{Fe}_{76.5} \mathrm{Si}_{13.5} \mathrm{~B}_{9} \mathrm{Cu}_{1}$ as compared with $\mathrm{Fe}_{77.5} \mathrm{Si}_{13.5} \mathrm{~B}_{9}$.

The above described computational results and analytical microscopy analyses indicated that metallic glass foils underwent quick heating to reach the peak temperature followed by 
severe cooling. The effect of such heating cycle on metallic glasses (crystallization and relaxation) would depend on the diffusion characteristics of the constituent elements present within the amorphous matrix. As the atomic radius increases from boron to niobium in the order $\mathrm{B}<\mathrm{Si}<\mathrm{Cu}<\mathrm{Nb}, \mathrm{B}$ would diffuse to much greater extent as compared to other elements. The atomic size effect coupled with the temperature variation during much shorter time (Fig.7) likely to decide the final microstructure as a result of laser treatment. As the atomic movements trigger with the rise in the temperature, the diffusion activity is likely to reach at the peak at $1087 \mathrm{~K}$ (the

highest temperature predicted). This further followed by rapid cooling $\left(\sim 10^{4} \mathrm{~K} / \mathrm{s}\right)$ may result in the premature arrest of the diffusion. Therefore, it is thought that metallic glass compositions of elements with higher atomic radii would be difficult to crystallize as a result of slower diffusion and dynamic temperature cycles. On the contrary, the compositions of alloying elements with smaller radii would crystallize relatively easy.

\section{Conclusion}

Laser annealing of amorphous melt-spun $\quad \mathrm{Fe}_{77.5} \mathrm{Si}_{13.5} \mathrm{~B}_{9}, \quad \mathrm{Fe}_{73.5} \mathrm{Si}_{13.5} \mathrm{~B}_{9} \mathrm{Nb}_{3} \mathrm{Cu}_{1}$, $\mathrm{Fe}_{74.5} \mathrm{Si}_{13.5} \mathrm{~B}_{9} \mathrm{Nb}_{3}$, and $\mathrm{Fe}_{73.5} \mathrm{Si}_{13.5} \mathrm{~B}_{9} \mathrm{Nb}_{3} \mathrm{Cu}_{1}$ (FINEMET) alloys, under identical conditions, revealed substantial differences in the de-vitrification behavior or the lack thereof of these alloys. While $\mathrm{Fe}_{77.5} \mathrm{Si}_{13.5} \mathrm{~B}_{9}$ and $\mathrm{Fe}_{76.5} \mathrm{Si}_{13.5} \mathrm{~B}_{9} \mathrm{Cu}_{1}$ partially de-vitrified exhibiting fine scale $\alpha-\mathrm{Fe}(\mathrm{Si})$ nanocrystals homogeneously distributed in an amorphous matrix, the $\mathrm{Fe}_{74.5} \mathrm{Si}_{13.5} \mathrm{~B}_{9} \mathrm{Nb}_{3}$, and $\mathrm{Fe}_{73.5} \mathrm{Si}_{13.5} \mathrm{~B}_{9} \mathrm{Nb}_{3} \mathrm{Cu}_{1}$ (FINEMET) alloys neither de-vitrified nor exhibited any perceivable compositional changes. The measured magnetic properties of these laser annealed alloys were consistent with the observed microstructures; $\mathrm{Fe}_{77.5} \mathrm{Si}_{13.5} \mathrm{~B}_{9}$ and $\mathrm{Fe} 76.5 \mathrm{Si13.5B} 9 \mathrm{Cu} 1$ exhibit higher saturation magnetization $\left(\mathrm{M}_{\mathrm{s}}\right)$ and coercivity $\left(\mathrm{H}_{\mathrm{c}}\right)$ values, while $\mathrm{Fe}_{74.5} \mathrm{Si}_{13.5} \mathrm{~B}_{9} \mathrm{Nb}_{3}$, and $\mathrm{Fe}_{73.5} \mathrm{Si}_{13.5} \mathrm{~B}_{9} \mathrm{Nb}_{3} \mathrm{Cu}_{1}$ (FINEMET) exhibited lower $\mathrm{M}_{\mathrm{s}}$ and $\mathrm{H}_{\mathrm{c}}$ values. Additionally, the presence 
of $\mathrm{Cu}$ in case of $\mathrm{Fe} 76.5 \mathrm{Si13.5B9Cu} 1$ caused $\mathrm{Cu}$ clustering prior to the onset of primary crystallization of $\alpha-\mathrm{Fe}(\mathrm{Si})$ nanocrystals, resulting in a marginally finer scale distribution of these nanocrystals as compared with the laser annealed $\mathrm{Fe}_{77.5} \mathrm{Si}_{13.5} \mathrm{~B}_{9}$ alloy.

\section{Acknowledgement}

This research (CX and RVR) is conducted by NTU-HUJ-BGU Nanomaterials for Energy and Water Management Programme under the Campus for Research Excellence and Technological Enterprise (CREATE), that was supported by the National Research Foundation, Prime Minister's Office, Singapore. The authors SSJ and NBD acknowledge the financial support from National Science Foundation (NSF-CMMI 0969249). The authors also gratefully acknowledge the Center for Advanced Research and Technology (CART) at the University of North Texas.

\section{References}

1. Zhang, Y. R., \& Ramanujan, R. V. (2006). A study of the crystallization behavior of an amorphous Fe 77.5 Si 13.5 B 9 alloy. Materials Science and Engineering: A, 416(1), 161-168.

2. Singhal, R., \& Majumdar, A. K. (1992). Crystallization of glassy Fe 80 B 20-x Si x (00 $\mathrm{x}$ ? 12) alloys. Journal of Magnetism and Magnetic Materials, 115(2), 245-249.

3. Gibson, M. A., \& Delamore, G. W. (1992). Nucleation kinetics of primary crystallization products in FeSiB metallic glasses. Journal of Materials Science,27(13), 3533-3538.

4. Mat'ko, I., Illeková, E., Švec, P., \& Duhaj, P. (1997). Crystallization characterisics in the Fe Si B glassy ribbon system. Materials Science and Engineering: A, 225(1), 145-152.

5. Chiriac, H., \& Marinescu, C. S. (2000). New position sensor based on ultraacoustic standing waves in FeSiB amorphous wires. Sensors and Actuators A: Physical, 81(1), 174-175. 
6. Ramanujan, R. V., \& Zhang, Y. R. (2006). Solid state dendrite formation in an amorphous magnetic Fe 77.5 Si 13.5 B 9 alloy observed by in situ hot stage transmission electron microscopy. Applied Physics Letters, 88(18), 182506-1-182506-3.

7. Herzer, G. (1990). Grain size dependence of coercivity and permeability in nanocrystalline ferromagnets. Magnetics, IEEE Transactions on, 26(5), 1397-1402.

8. Herzer, G. (1997). Nanocrystalline soft magnetic alloys. Handbook of Magnetic Materials, 10, 415-462.

9. Yoshizawa, Y., Oguma, S., \& Yamauchi, K. (1988). New Fe-based soft magnetic alloys composed of ultrafine grain structure. Journal of Applied Physics, 64(10), 6044-6046.

10. Hono, K., Ping, D. H., Ohnuma, M., \& Onodera, H. (1999). Cu clustering and Si partitioning in the early crystallization stage of an Fe $73.5 \mathrm{Si} 13.5 \mathrm{~B} 9 \mathrm{Nb} 3 \mathrm{Cu} 1$ amorphous alloy. Acta Materialia, 47(3), 997-1006.

11. Ohnuma, M., Hono, K., Linderoth, S., Pedersen, J. S., Yoshizawa, Y., \& Onodera, H. (2000). Small-angle neutron scattering and differential scanning calorimetry studies on the copper clustering stage of $\mathrm{Fe}-\mathrm{Si}-\mathrm{B}-\mathrm{Nb}-\mathrm{Cu}$ nanocrystalline alloys. Acta Materialia, 48(20), 4783-4790.

12. Hono, K., Li, J. L., Ueki, Y., Inoue, A., \& Sakurai, T. (1993). Atom probe study of the crystallization process of an Fe 73.5 Si $13.5 \mathrm{~B} 9 \mathrm{Nb} 3 \mathrm{Cu} 1$ amorphous alloy. Applied Surface Science, 67(1), 398-406.

13. Hono, K., Zhang, Y., Inoue, A., \& Sakurai, T. (1995). Atom probe studies of nanocrystalline microstructural evolution in some amorphous alloys. Materials Transactions, JIM, 36(7), 909-917.

14. Ayers, J. D., Harris, V. G., Sprague, J. A., Elam, W. T., \& Jones, H. N. (1998). On the formation of nanocrystals in the soft magnetic alloy Fe $73.5 \mathrm{Nb} 3 \mathrm{Cu} 1 \mathrm{Si} 13.5 \mathrm{~B}$ 9. Acta Materialia, 46(6), 1861-1874.

15. Ayers, J. D., Harris, V. G., Sprague, J. A., Elam, W. T., \& Jones, H. N. (1997). A model for nucleation of nanocrystals in the soft magnetic alloy Fe $73.5 \mathrm{Nb} 3 \mathrm{Cu} 1 \mathrm{Si} 13.5 \mathrm{~B}$ 9. Nanostructured Materials, 9(1), 391-396.

16. Zhang, Y. R., \& Ramanujan, R. V. (2006). Microstructural observations of the crystallization of amorphous Fe-Si-B based magnetic alloys. Thin Solid Films,505(1), 97-102. 
17. Herzer, G., Fähnle, M., Egami, T., \& Kronmüller, H. (1980). Micromagnetic Theory of Phase Transitions in Inhomogeneous Ferromagnets III. Non-Local Landau-Ginzburg Theory. Physica Status Solidi (b), 101(2), 713-721.

18. Pradeep, K. G., Herzer, G., Choi, P., \& Raabe, D. (2014). Atom probe tomography study of ultrahigh nanocrystallization rates in $\mathrm{FeSiNbBCu}$ soft magnetic amorphous alloys on rapid annealing. Acta Materialia, 68, 295-309.

19. Chrobak, A., Chrobak, D., Haneczok, G., Kwapuliński, P., Kwolek, Z., \& Karolus, M. (2004). Influence of $\mathrm{Nb}$ on the first stage of crystallization in Fe 86- x $\mathrm{Nb}$ x B 14 amorphous alloys. Materials Science and Engineering: A, 382(1), 401-406.

20. Katakam, S., Hwang, J. Y., Vora, H., Harimkar, S. P., Banerjee, R., \& Dahotre, N. B. (2012). Laser-induced thermal and spatial nanocrystallization of amorphous $\mathrm{Fe}-\mathrm{Si}-\mathrm{B}$ alloy. Scripta Materialia, 66(8), 538-541.

21. Katakam, S., Santhanakrishnan, S., Vora, H., Hwang, J. Y., Banerjee, R., \& Dahotre, N. B. (2012). Stress-induced selective nano-crystallization in laser-processed amorphous Fe-Si-B alloys. Philosophical Magazine Letters, 92(11), 617-624.

22. Smith, C., Katakam, S., Nag, S., Chen, X., Ramanujan, R. V., Dahotre, N. B., \& Banerjee, R. (2014). Improved soft magnetic properties by laser de-vitrification of $\mathrm{Fe}-\mathrm{Si}$ B amorphous magnetic alloys. Materials Letters, 122, 155-158.

23. Katakam, S., Devaraj, A., Bowden, M., Santhanakrishnan, S., Smith, C., Ramanujan, R. V., ... \& Dahotre, N. B. (2013). Laser assisted crystallization of ferromagnetic amorphous ribbons: A multimodal characterization and thermal model study. Journal of Applied Physics, 114(18), 184901.

24. Katakam, S., \& Dahotre, N. (2014). Laser patterning of Fe-Si-B amorphous ribbons in magnetic field. Applied Physics A, 117(3), 1241-1247.

25. S. Katakam, Laser Surface Treatment of Amorphous Metals, Ph.D. thesis, University of North Texas (2014).

26. Costa, L., Vilar, R., Reti, T., \& Deus, A. M. (2005). Rapid tooling by laser powder deposition: Process simulation using finite element analysis. Acta Materialia, 53(14), 3987-3999.

27. Totten, G. E., \& Howes, M. A. (Eds.). (1997). Steel heat treatment handbook. CRC Press. 
28. Santhanakrishnan, S., Kong, F., \& Kovacevic, R. (2011). An experimentally based thermo-kinetic hardening model for high power direct diode laser cladding. Journal of Materials Processing Technology, 211(7), 1247-1259.

29. Kannatey-Asibu Jr, E. (2009). Principles of Laser Materials Processing (Vol. 4). John Wiley \& Sons, New York.

30. Smith, C., Katakam, S., Nag, S., Zhang, Y. R., Law, J. Y., Ramanujan, R. V., ... \& Banerjee, R. (2014). Comparison of the crystallization behavior of Fe-Si-B-Cu and Fe-SiB-Cu-Nb-based amorphous soft magnetic alloys. Metallurgical and Materials Transactions A, 45(7), 2998-3009.

31. Herzer, G. (2013). Modern soft magnets: amorphous and nanocrystalline materials. Acta Materialia, 61(3), 718-734. 


\section{Tables}

Table I: Coercivity $\left(\mathrm{H}_{\mathrm{c}}\right)$ and Saturation Magnetization $\left(\mathrm{M}_{\mathrm{s}}\right)$ values for all laser annealed compositions

\begin{tabular}{|c|c|c|}
\hline Sample & $\mathbf{H}_{\mathbf{c}}(\mathbf{A} / \mathbf{m})$ & $\mathbf{M}_{\mathbf{s}}(\mathbf{e m u} / \mathbf{g})$ \\
\hline Fe-Si-B & 581 & 117 \\
\hline Fe-Si-B-Cu & 271 & 124 \\
\hline Fe-Si-B-Nb & 88 & 103 \\
\hline Fe-Si-B-Cu-Nb (Finemet) & 72 & 109 \\
\hline
\end{tabular}

Table II: Thermo-physical properties employed in the FE model

\begin{tabular}{lll}
\hline Symbol & Description & Value \\
$\boldsymbol{\rho}$ & Density & $7.18 \mathrm{~g} / \mathrm{cm}^{3}[5]$ \\
$\mathbf{C}_{\boldsymbol{P}}$ & Specific heat capacity & $500 \mathrm{~J} / \mathrm{kgK}[10]$ \\
$\mathbf{k}$ & Thermal conductivity & $9 \mathrm{~W} / \mathrm{m} / \mathrm{K}[11,12]$ \\
$\boldsymbol{\varepsilon}$ & Emissivity & 0.7 \\
$\mathbf{h}$ & Convective heat transfer & $10 \mathrm{~W} / \mathrm{m}^{2} \mathrm{~K}$ \\
& coefficient & \\
\hline
\end{tabular}




\section{Figure Captions}

Fig. 1: XRD patterns of laser annealed (a) Fe-Si-B (b) Fe-Si-B-Cu (c) Fe-Si-B-Nb, and (d) Fe$\mathrm{Si}-\mathrm{B}-\mathrm{Cu}-\mathrm{Nb}$ (Finemet) ribbons.

Fig. 2: (a) Selected area diffraction (SAD) pattern, (b) lower magnification dark-field image, and (c) higher magnification dark-field image, respectively from the $\mathrm{Fe}_{77.5} \mathrm{Si}_{13.5} \mathrm{~B}_{9}$ alloy, (d), (e), and (f) selected area diffraction (SAD) pattern, lower magnification dark-field image, and higher magnification dark-field image, respectively from the $\mathrm{Fe}_{76.5} \mathrm{Si}_{13.5} \mathrm{~B}_{9} \mathrm{Cu}_{1}$ alloy.

Fig. 3: Atom probe tomography analysis of Fe-Si-B. a) $10 \mathrm{~nm}$ slice of the reconstruction with $100 \%$ of $\mathrm{Cu}, \mathrm{Si}$, and $\mathrm{B}$ ions b) Interface of the nano-crystalline $\mathrm{Fe}_{3} \mathrm{Si}$ and amorphous matrix is delineated by at- $11 \% \mathrm{Si}$ iso-surface d) Proxigram generated from $\mathrm{Si}$ at-11\% iso-surface.

Fig. 4: Atom probe tomography analysis of $\mathrm{Fe}-\mathrm{Si}-\mathrm{B}-\mathrm{Cu}$. a) $10 \mathrm{~nm}$ slice of the reconstruction with $100 \%$ of $\mathrm{Cu}, \mathrm{Si}, \& \mathrm{~B}$ ions and b) interface of the nano-crystalline $\mathrm{Fe}_{3} \mathrm{Si}$ and amorphous matrix is delineated by at-11\% $\mathrm{Si}$ iso-surface. $\mathrm{Cu}$ clusters are observed by at-4\% $\mathrm{Cu}$ iso-surface. c) $90^{\circ}$ rotated view of (b), d) proxigram generated from $\mathrm{Si}$ at-11\% iso-surface, e) 1D composition profile along the length of the cylinder (inset), f) 1D composition profile along the length of the cylinder (inset). The cylinders in (e) \& (f) are at perpendicular to each other.

Fig. 5: Atom probe tomography analysis of Fe-Si-B-Nb and Fe-Si-B-Cu-Nb. a) Fe-Si-B-Nb. 10 $\mathrm{nm}$ slice of the reconstruction with $100 \%$ of $\mathrm{Nb}, \mathrm{Si}, \& \mathrm{~B}$ ions, b) composition along the length of the cylinder in (a), c) Fe-Si-B-Cu-N $10 \mathrm{~nm}$ slice of the reconstruction with $100 \%$ of $\mathrm{Nb}, \mathrm{Cu}, \mathrm{Si}$, $\&$ B ions, and d) composition along the length of the cylinder in (c)

Fig. 6: VSM results of laser annealed Fe-Si-B, Fe-Si-B-Cu, Fe-Si-B-Nb, and Fe-Si-B-Cu-Nb (Finemet) ribbons.

Fig. 7: Peak temperature of laser annealed $\mathrm{Fe}-\mathrm{Si}-\mathrm{B}$ ribbon predicted by the thermal model. 
$\begin{array}{lllllllllllllll}20 & 25 & 30 & 35 & 40 & 45 & 50 & 55 & 60 & 65 & 70 & 75 & 80 & 85 & 90\end{array}$

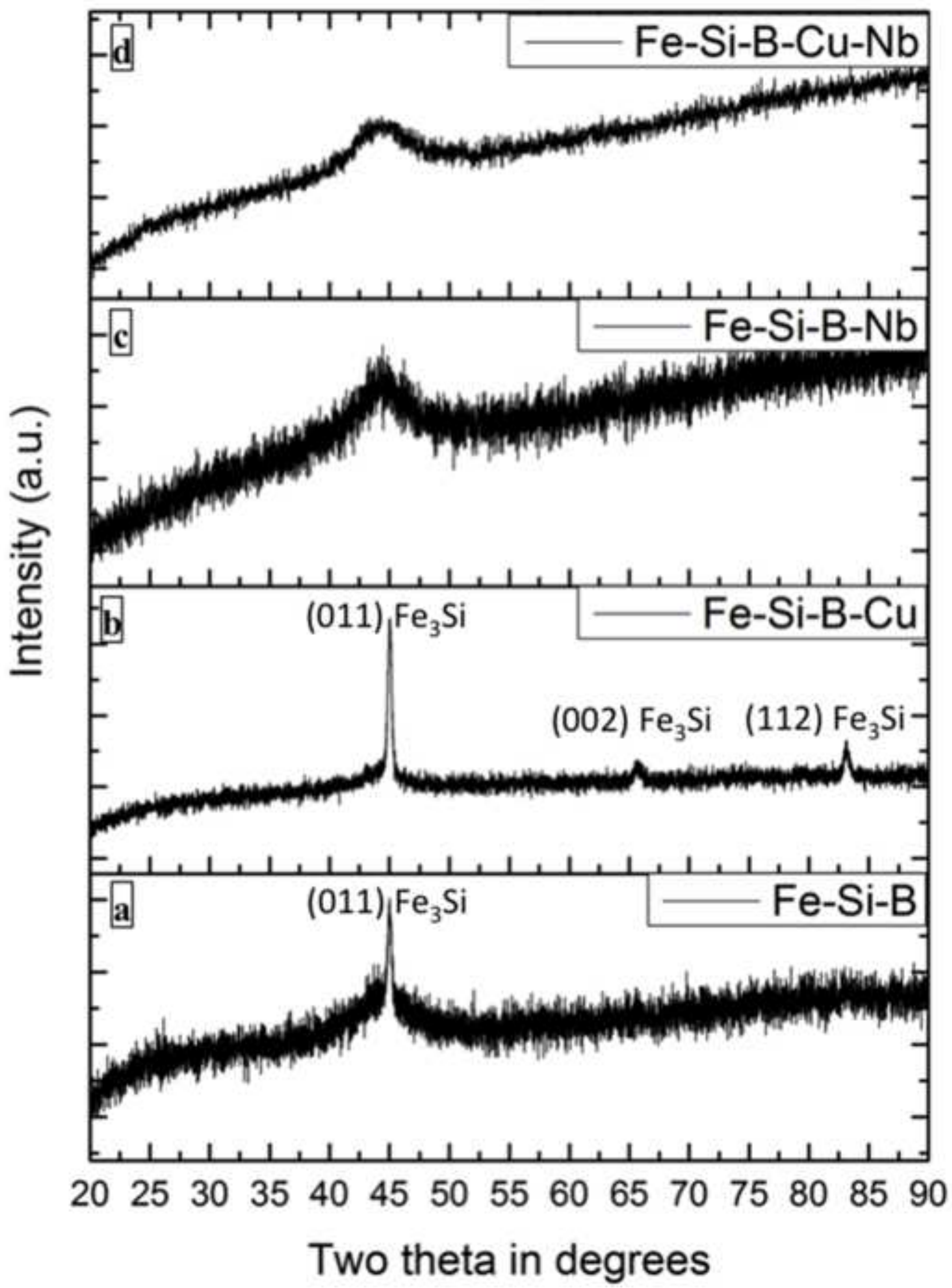




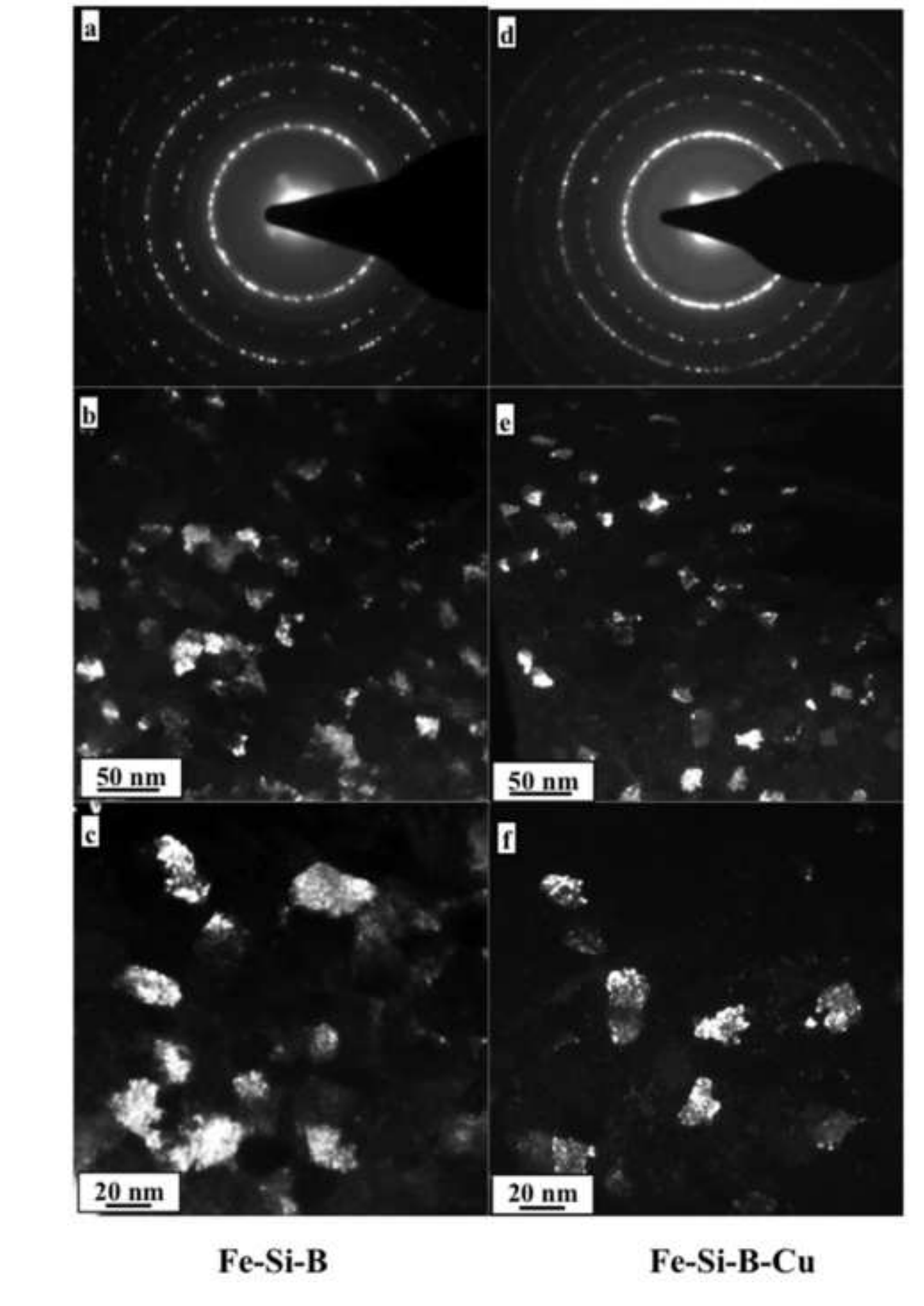

Figure 2

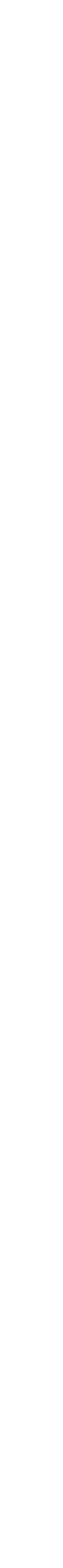

\section{Fure 2}

2

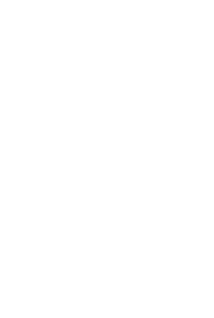



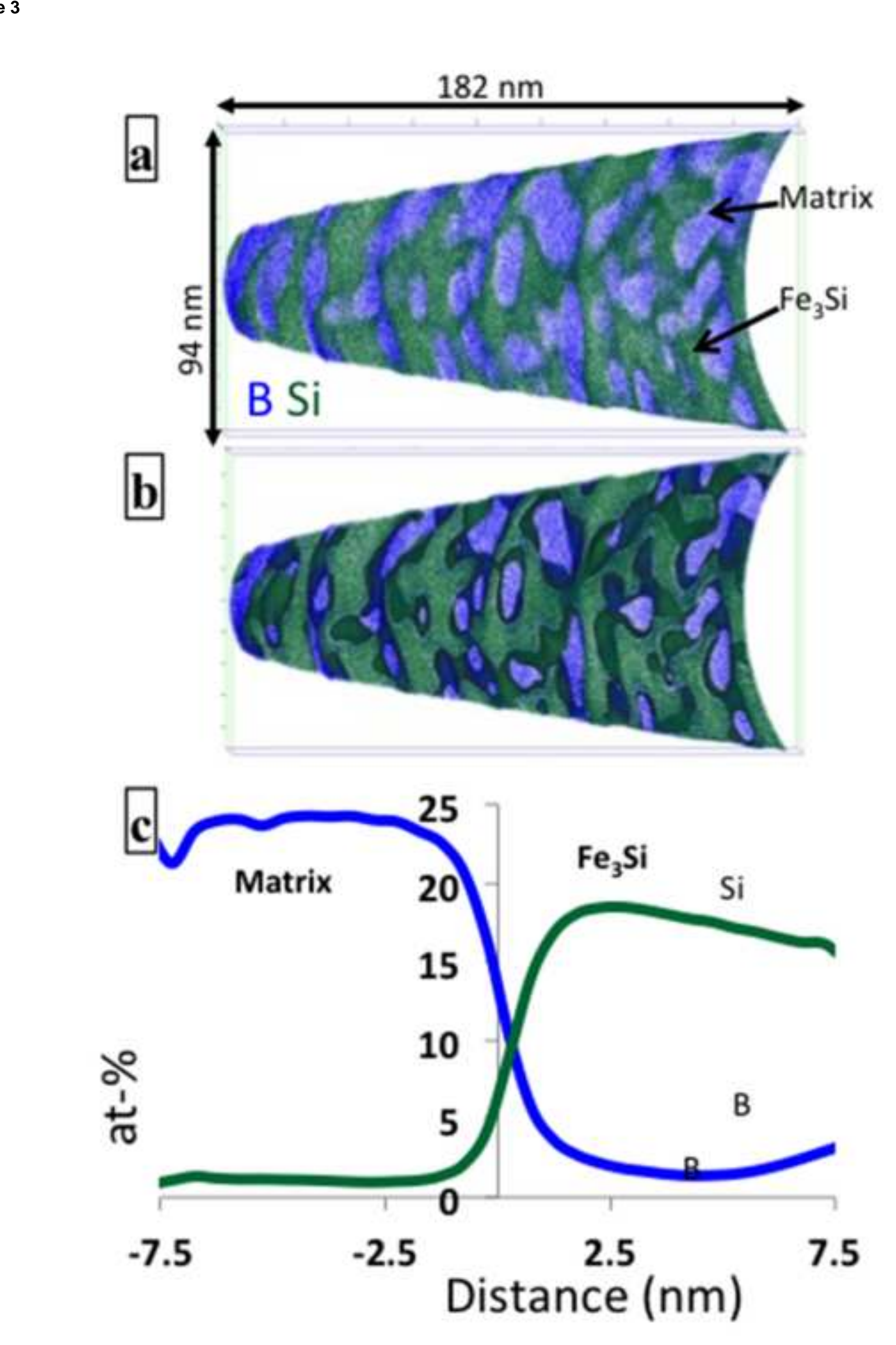

Figure 3
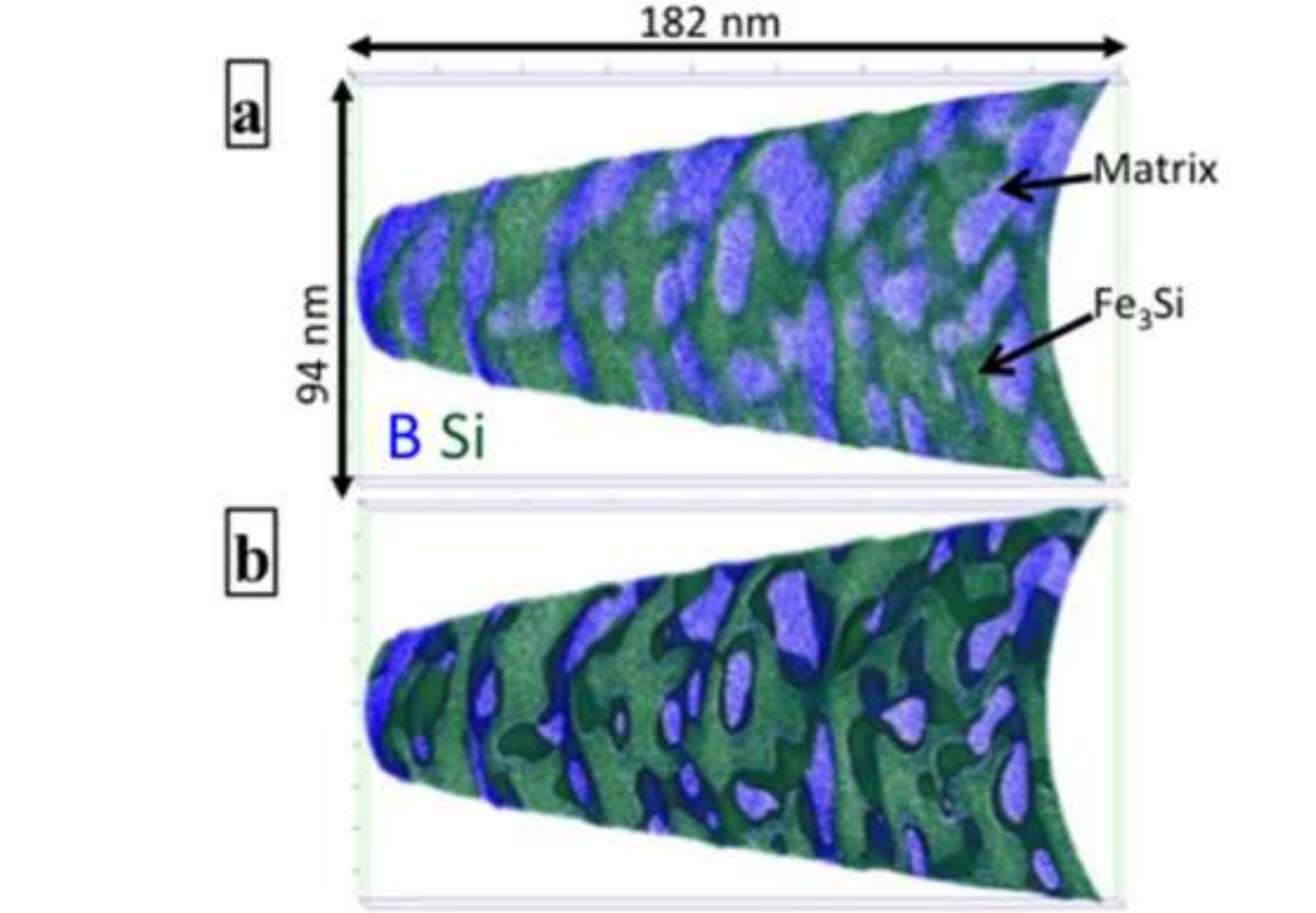

Figure 3

Figure

Figure

3


Figure 4

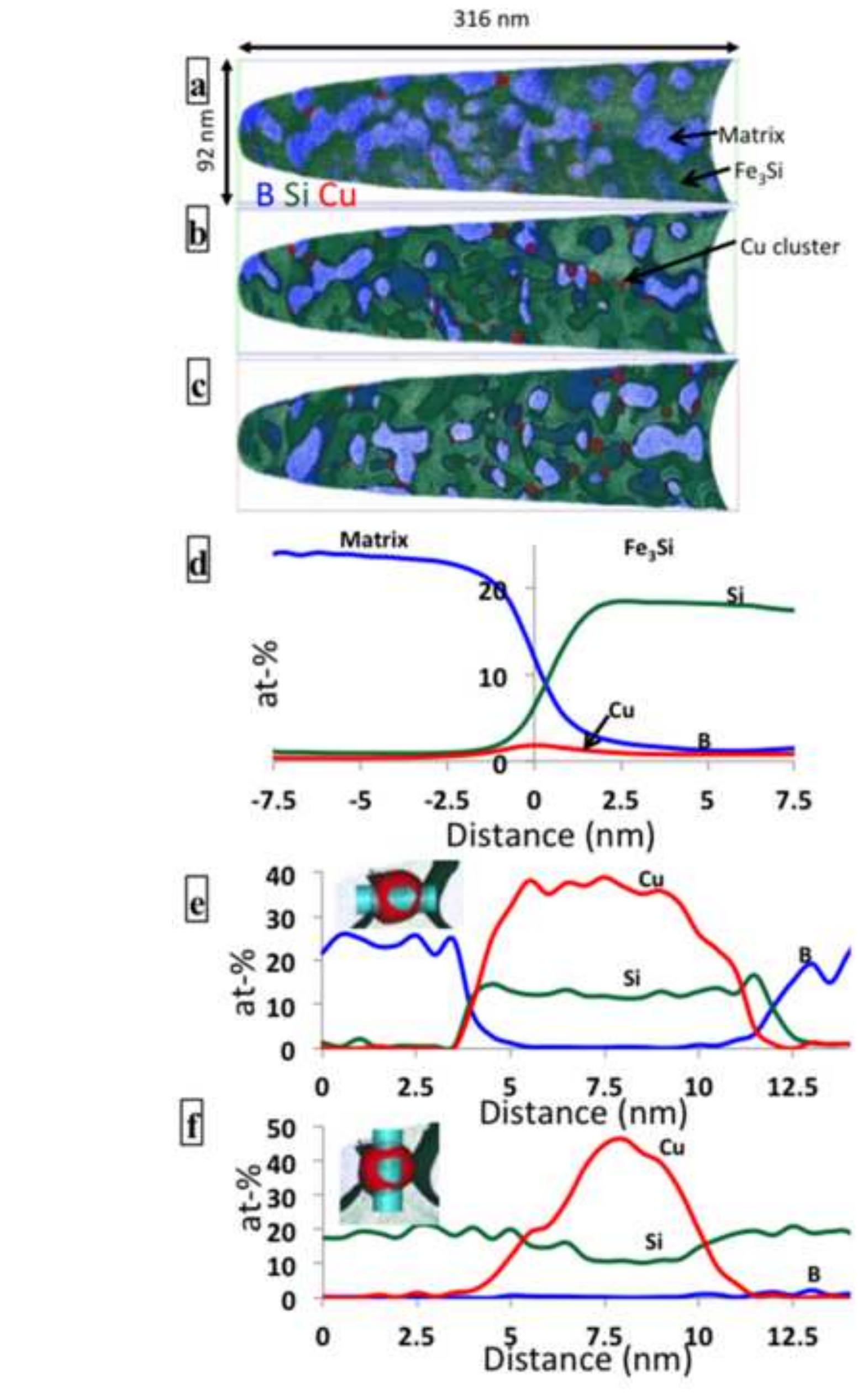

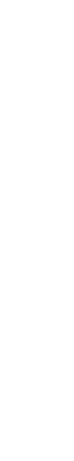


$316 \mathrm{~nm}$

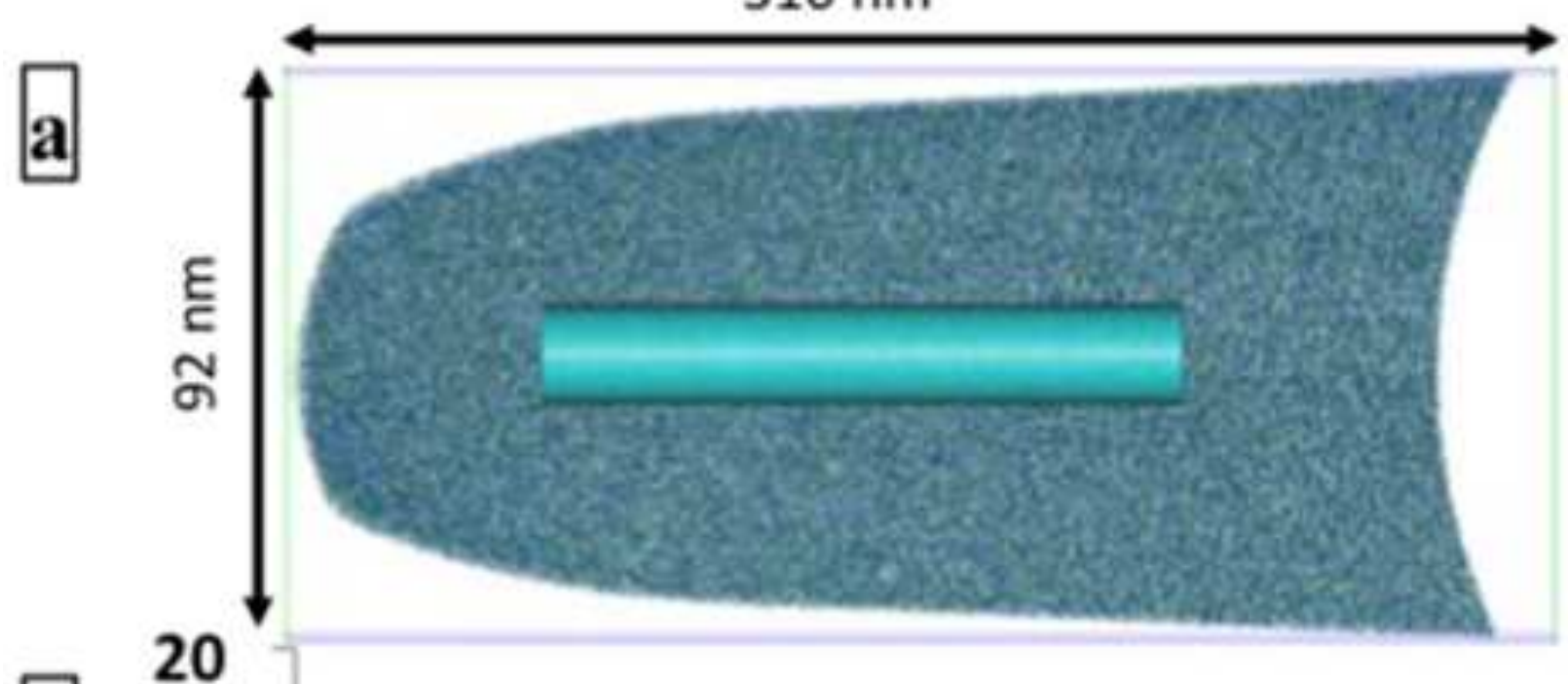

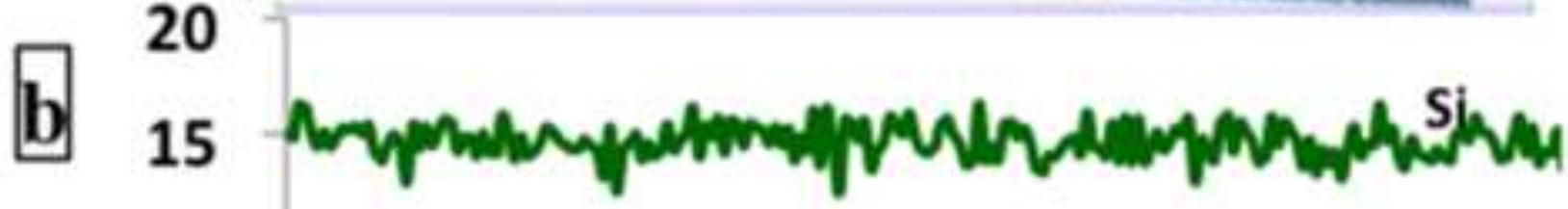

$0^{10}$ m

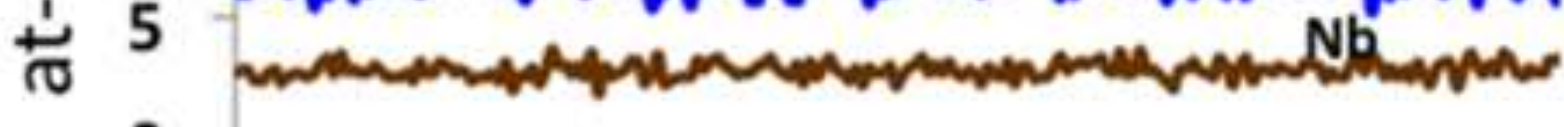

0

$\begin{array}{llll}0 & 10 & 20 & 30\end{array}$

c

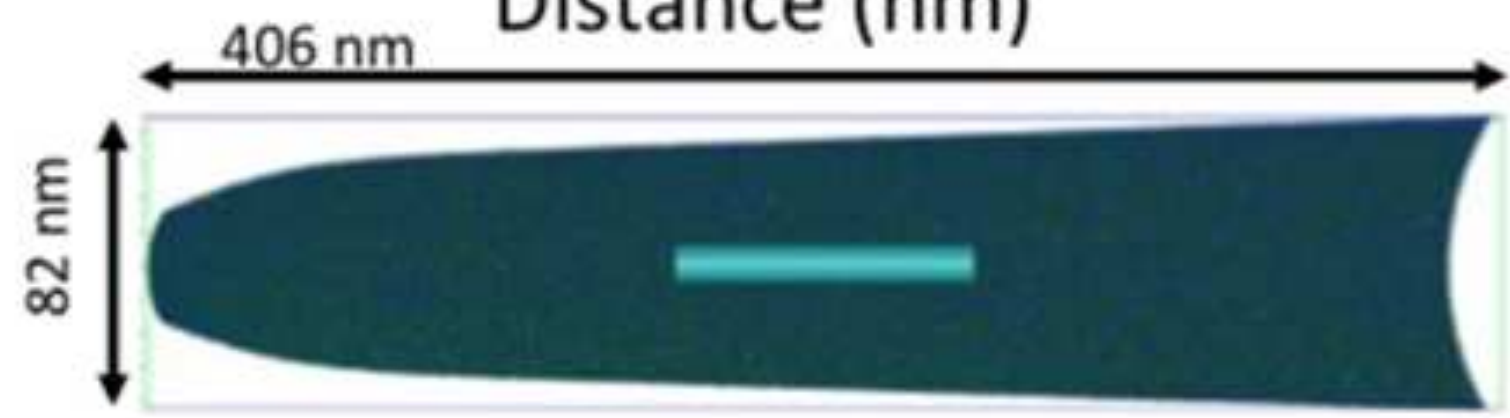

$40 \quad 50$

\section{Distance $(\mathrm{nm})$}

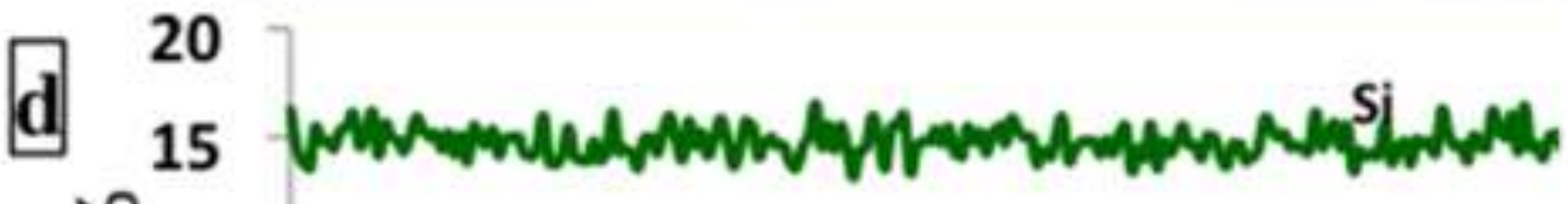
这10

0
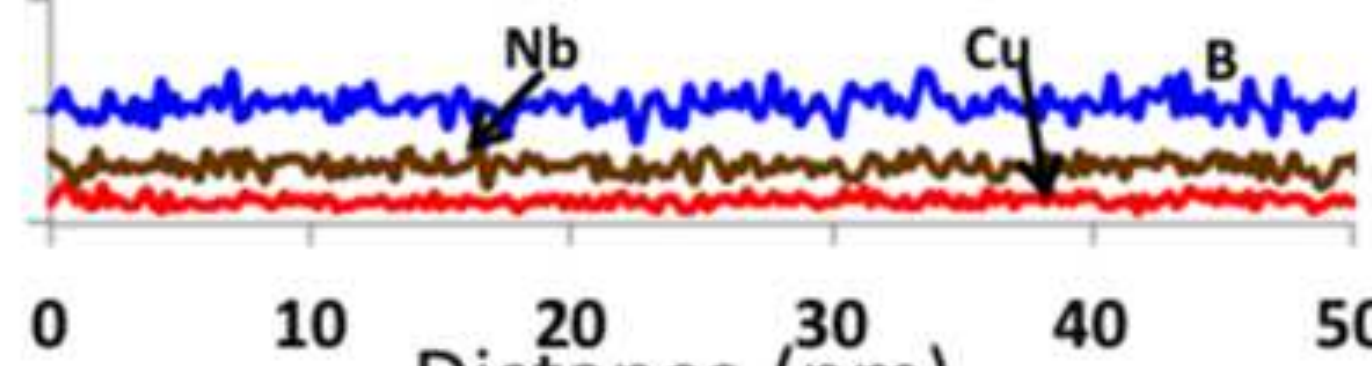

Distance $(\stackrel{20}{\mathrm{~nm}})$

40

50 


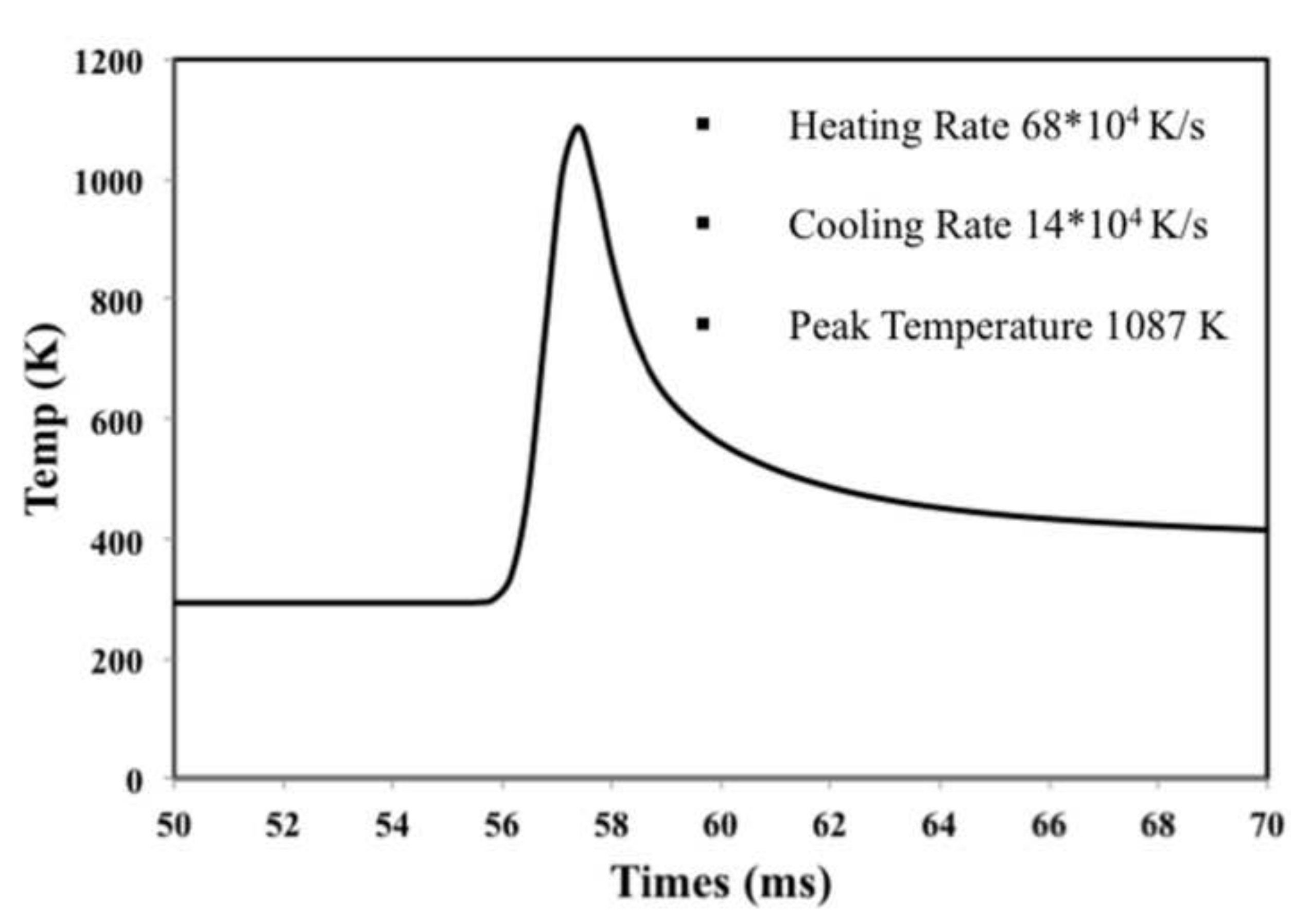




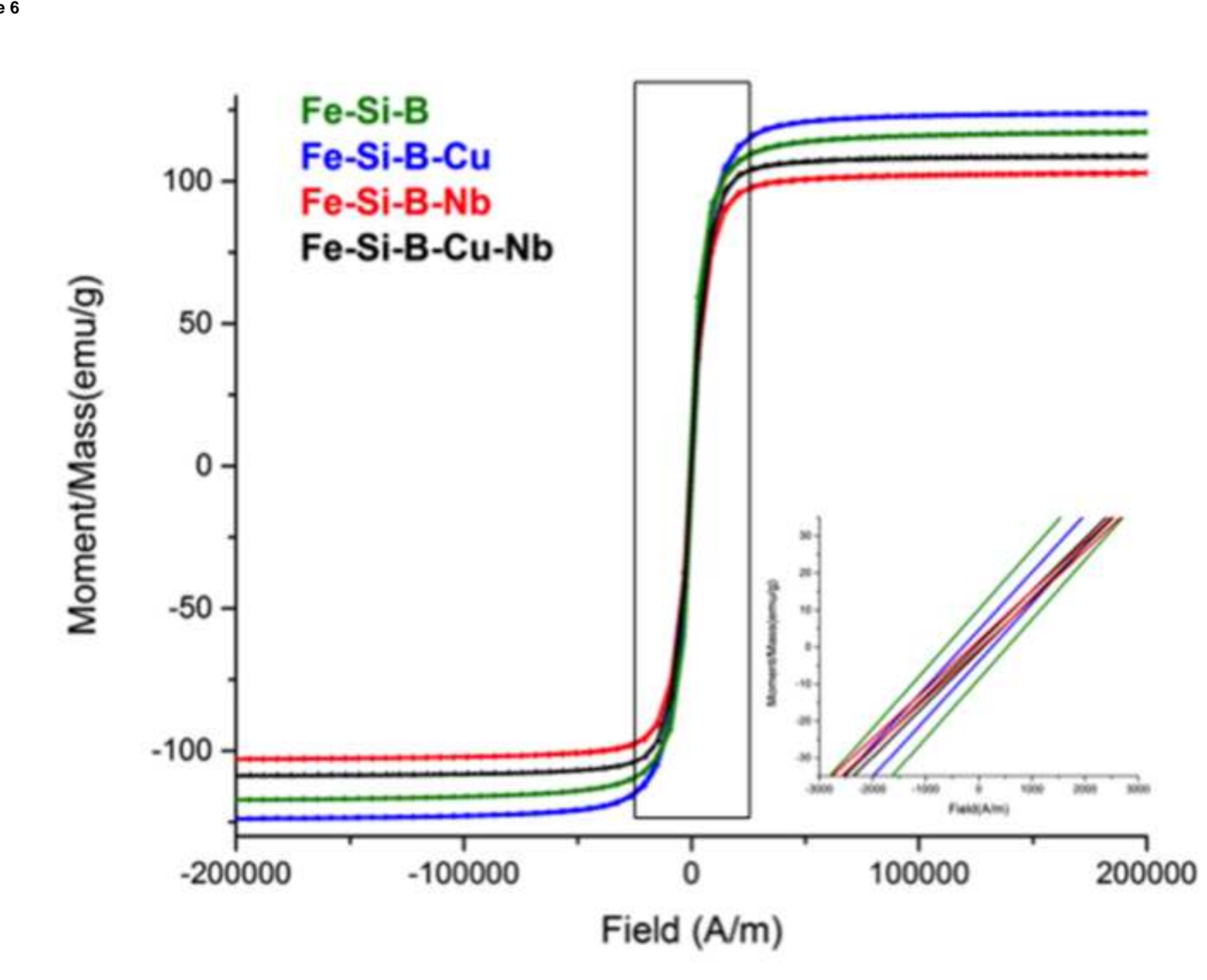

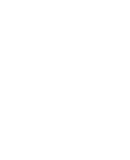

